\title{
Passo a passo do trabalho pericial
}

\author{
Leonardo Levin
}

Levin L. Passo a passo do trabalho pericial. Saúde, Ética \& Justiça. 2012;17(1):38-41.

RESUMO: Neste artigo discorre-se a respeito da especificidade do trabalho do perito médico, especialmente nas perícias referentes à saúde do trabalhador. São retomados princípios que regem esta atividade bem como critérios a serem seguidos pelos peritos.

PALAVRAS CHAVE: Laudo pericial; Medicina legal; Medicina do trabalho; Metodologias de avaliação de danos.

Médico Legista do Instituto Médico Legal de São Paulo. Diretor Técnico de Serviços do Núcleo de Perícias Médico Legais de Presidente Prudente, SP. Professor de Medicina Legal da Academia de Polícia da Polícia Civil de São Paulo - ACADEPOL, SP.

Endereço para correspondência: leonardolevin@uol.com.brou leonardolevin@gmail.com 
A convicção pericial embute um perene dever de fundamentar 0 seu entendimento da existência de relação causal (negativa ou positiva) entre o dano corporal e o alegado ato causador (do dano).

Muito já se falou e se escreveu quanto à metodologia para a isso satisfazer. Inclusive, - Conselho Federal de Medicina, através da Resolução CFM no 1488/1998 (modificada pelas Resoluções CFM nำ 1.810/2006 e CFM no 1.940/2010), constituiu normas específicas para os médicos que atendam ao trabalhador. Com tal redação, os organismos administrativos da prática médica fizeram excludentes todos os demais médicos que se debrucem nestas mesmas necessidades, com atividades funcionais que não sejam as de atender ao trabalhador.

Melhor!

Particularmente entendo que deva ir além disso a abrangência do trabalho pericial que, ao invés de atender ao trabalhador, atende à Justiça, seja no intercurso de um inquérito ou de um processo. E a forma mais exaustiva que antevejo para tal é a conjugação dos ditames das escolas Italiana ${ }^{1}$ e Espanhola ${ }^{2}$.

Quanto ao nexo, a escola Italiana definiu os critérios e a escola Espanhola listou os elementos necessários. Assim, o nexo da causalidade no trabalho pericial resta mais completamente satisfeito através de tais critérios e elementos que, bem definidos, constituem a metodologia (ou o passo a passo) do trabalho pericial.

Os critérios são:

1. Critério cronológico: diz respeito à idade cicatricial ou à evolução natural do dano. É a relação temporal entre o evento alegado e o momento da ocorrência + existência ou não de concausa prévia + a evolução natural da lesão até o dia da Perícia. Toda alteração transitória ou permanente de função (também conhecida como lesão), no todo ou em parte do indivíduo, tem uma evolução natural e esperada entre o evento alegado e o dia do exame pericial.

Exemplo: o Periciado menor de idade que apresenta múltiplas lesões com idades cicatriciais diversas permite a indução de que se deva investigar a Síndrome da Criança Espancada.

2. Critério topográfico: é a exigida correspondência da estrutura lesada com o alegado dano causador, inclusive o mecanismo de lesão e o instrumento ou meio que a produziu.
Exemplo: um corpo estranho conjuntival (fiapo de cana que fere a conjuntiva do cortador de cana) é incapaz em dar causa à doença degenerativa macular.

3. Critério da Adequação Lesiva: é o estudo da íntima relação ação / reação ou mecanismo do trauma / dano produzido.

Exemplo: uma lesão de menisco exige que o alegado mecanismo de trauma seja torção do joelho, ao passo que um trauma direto no joelho (em batente de caminhão, por exemplo) produzirá, no máximo, uma contusão da patela.

\section{Critério de Continuidade Fenomeno-} lógica: é o estudo da íntima relação ação / reação ou aparecimento da manifestação (emocional, corporal ou funcional) / exposição ao agente causador. Ou melhor, a cadeia de eventos narrados pela parte autora deve ter uma lógica de continuidade.

Exemplo: o periciado que alega ter sofrido agressão e queda com consequente dor aguda nas costas e incapacidade laboral específica e vem à perícia 06 meses após trazendo exame de imagem de espondilolistese L5-S1 mas, no entanto, o perito constata massa muscular preservada em membros e inexistencia de qualquer internação por fratura de corpo vertebral. A única possibilidade pericial é de a espondilolistese ser concausa prévia e o alegado desuso, somente um discurso.

\section{Critério de Exclusão de Outras Causas} (diagnose diferencial): este é o campo em que o perito examina os possíveis diferenciais da alegada lesão.

Exemplo: em processo judicial trabalhista no qual o periciado de 43 anos, que trabalhou por 25 anos movimentando cargas em empresa de logistica, apresentou queixa de osteoartrose de joelho direito e de tornozelo esquerdo. O Assitente Técnico identificou a predominância do hemisfério cerebral (que era esquerda para pé) e mensurou as medidas antropométricas dos segmentos corporais de membros inferiores, comprovando tal predominância, e não identificou desuso sendo que, por final, na perquirição, Ihe foi testemunhado pelo periciado que ele sempre teve uma atividade paralela, 03 vezes por semana e, desde os seus 16 anos, era volante de clube de futebol de várzea.

6. Critério Epidemiológico ou Estatístico: é o estudo da íntima relação entre a prevalência do achado pericial e alguma frequência pré- 
estabelecida a fim de aferir existência, ou não, de qualquer discrepância entre o dano apresentado e a alegada ação causadora.

Exemplo: ao se correlacionar o CID (ou CID's) apresentado(s) no exame pericial com a alegada função laboral causadora (como, por exemplo, o CNAE 7 das Empresas).

Os Elementos são:

1. Os elementos próprios no nível do alegado evento: a história relatada pela parte autora deve embutir as exigências da cadeia de critérios já estudados. Ou seja, os achados clínicos no dia da perícia devem excluir qualquer possibilidade de resultar numa forma espontânea idiossincrática do periciado.

2. Os elementos próprios no nível das alegações da parte autora: inexiste aparelho para mensurar simulação e metassimulação; assim, deve-se, em primeiro lugar, proceder a um exame clínico cuidadoso e demorado, valorizando-se os sintomas coerentes, as manifestações falsas, as incoerências intrínsecas, os artifícios engenhosos, a falta de cooperação ao exame, falta de memória para datas, os antecedentes anti-sociais do examinado e a sintomatologia absurda. Levar em conta o mutismo obstinado, a confusão mental massiva e atitudes extravagantes.

3. Os elementos próprios no nível das constatações pessoais do perito: ao conjunto dos elementos periciais observados pela perícia alia-se o fato de o perito poder vistoriar, ou não, o local do evento. Tal possibilidade o perito decidirá por moto próprio, ou em cumprimento de formal decisun judicis.

Porém, para que esteja bem definido o rol de deveres do perito, necessário é separar seja ele representante de empresa privada ou pública. E isto reside nas letras do artigo 37 da Constituição Brasileira que constituiu os princípios fundamentais da empresa pública.

Para simplificar, cabe o resumo desta diferença: enquanto o representante da empresa privada pode tudo fazer desde que ilegal não seja, o da empresa pública somente pode fazer aquilo que tenha a expressa previsão legal.

E, sobre previsão legal, devemos nos limitar ao conjunto de normas do Direito Constituído e Consuetudinário sendo, entretanto, absolutamente fiel à "caneta do Juiz".
As principais normas:

\section{Quanto ao universo do trabalho pericial:}

\section{Código de Processo Penal}

Art. 160 - Os peritos elaborarão o laudo pericial, onde descreverão minuciosamente $o$ que examinarem e responderão aos quesitos formulados.

Parágrafo único - O laudo pericial será elaborado no prazo máximo de 10 (dez) dias, podendo este prazo ser prorrogado, em casos excepcionais, a requerimento dos peritos.

Ou seja, $\mathrm{n}^{\circ} 01$ :

$\left.1^{\circ}\right)$ Descrever o que foi observado e

$2^{\circ}$ ) Responder aos quesitos formulados.

$\mathrm{E}$, neste tópico, há de se atentar que não deve o perito apenas redigir a resposta, mas sempre e de primeiro, apresentar o quesito para em seguida redigir a resposta. Acaso assim não o fizer, - leitor será obrigado a ficar folheando os autos até encontrar a redação do quesito. E isso, é claro, produz desnecessária perda de tempo e produção daquele pequeno ânimo de "querer esganar o perito".

3) Entregar o laudo no prazo máximo de até 10 dias, independentemente de estar solicitado no Inquérito Policial ou no Processo.

Deve ser observado que a letra da Lei não explicita que o laudo deva ser conclusivo.

Assim, é dever do perito entregar o laudo inicial neste interregno de até dez dias a fim de "soltar" o trabalho policial judiciário ou do próprio Poder Judiciário. Acaso o laudo não seja conclusivo, deve ele assinalar que se aguarda o resultado dos exames complementares solicitados (conforme explicitados em campo próprio do laudo inicial).

\section{Quanto à conduta do perito:}

\section{Código de Processo Civil}

Art. 422-Operito cumprirá escrupulosamente o encargo que Ihe foi cometido, independentemente de termo de compromisso. Os assistentes técnicos são de confiança da parte, não sujeitos a impedimento ou suspeição.

(Alterado pela L-008.455-1992)

Art. 429 - Para o desempenho de sua função, podem o perito e os assistentes técnicos utilizar-se de todos os meios necessários, ouvindo testemunhas, obtendo informações, solicitando documentos que estejam em poder de parte ou em repartições públicas, bem como instruir o laudo com plantas, desenhos, fotografias e outras quaisquer peças. 
Art. 435 - A parte que desejar esclarecimento do perito e do assistente técnico requererá ao juiz que mande intimá-lo a comparecer à audiência, formulando desde logo as perguntas, sob forma de quesitos.

Parágrafo único - O perito e o assistente técnico só estarão obrigados a prestar os esclarecimentos a que se refere este artigo, quando intimados 5 (cinco) dias antes da audiência.

Art. 436 - O juiz não está adstrito ao laudo pericial, podendo formar a sua convicção com outros elementos ou fatos provados nos autos.

\section{Ou seja, $n^{\circ} 02$ :}

As ferramentas do trabalho pericial estão explicitadas no artigo 429 do CPC.

Porém, o perito não pode ser transformado em coletor de prova (seja testemunhal ou de outros elementos).

Aliás, o perito nunca constitui a prova, pois isso seria crime; somente a ilumina.

A prova sempre existe e o que falta é quem a saiba identificar.
Este é o seu trabalho pericial: iluminar a prova e materializá-la através do laudo.

Isto é feito para que as partes e o presidente dos autos (seja Inquérito Policial ou Processo) observem-nas e as possam usar na consecução de seus objetivos.

A prova sempre já existe. Apenas não foi observada como tal.

Leia-se: "passou batido".

Tanto isso é verdade que toda a prova testemunhal apresentada pelo laudo deve nominar a fonte da informação para que possa ser reproduzida em Juízo (RP 43/289 à p. 290), pois somente assim será reconhecida como verdade.

E neste tópico reside a explicação de tantos peritos serem convocados para prestar depoimento oral à frente do Juiz, pois toda a vez em que o campo "Histórico" do laudo apresentar informação que não esteja precedida dos verbetes "Refere fulano de tal que" e acaso o presidente ou alguma das partes entendam relevante tal informação, o perito será convocado para dizer como e de quem ele a obteve.

Levin L. Passo a passo do trabalho pericial. Saúde, Ética \& Justiça. 2012;17(1):38-41.

ABSTRACT: This article discusses the specificity of the medical expert activity, especially in expertise related to workers' health. Some principles that rule this activity are exposed as well as the main criteria to be followed by the experts.

KEY-WORDS: Expert testimony; Forensic medicine; Occupational medicine; Damage assessment methodologies.

\section{REFERÊNCIAS}

2. Gisbert Calabuig JA. Medicina legal y toxicologia. 5a ed. Barcelona: Masson; 1998.
1. Franchini A. Medicina legale. 10a ed. Padua: CEDAM; 1985. 